\title{
Insulin signaling and the regulation of insect diapause
}

\author{
Cheolho Sim ${ }^{1 *}$ and David L. Denlinger ${ }^{2 *}$ \\ 1 Department of Biology, Baylor University, Waco, TX, USA \\ ${ }^{2}$ Departments of Entomology and Evolution, Ecology, and Organismal Biology, Ohio State University, Columbus, OH, USA
}

\section{Edited by:}

Xanthe Vafopoulou, York University,

Canada

Reviewed by:

Hong Lei, University of Arizona, USA

Michael Strand, University of

Georgia, USA

${ }^{*}$ Correspondence:

Cheolho Sim, Department of Biology, Baylor University, A119,

Baylor Science Building, 101 Bagby

Avenue, Waco, TX 76798, USA

e-mail: cheolho_sim@baylor.edu;

David L. Denlinger, Departments of Entomology and Evolution, Ecology, and Organismal Biology, Ohio State University, 300 Aronoff Laboratory, 318 West 12 th Avenue, Columbus, $\mathrm{OH}$ 43210, USA

e-mail:denlinger.1@osu.edu
A rich chapter in the history of insect endocrinology has focused on hormonal control of diapause, especially the major roles played by juvenile hormones (JHs), ecdysteroids, and the neuropeptides that govern JH and ecdysteroid synthesis. More recently, experiments with adult diapause in Drosophila melanogaster and the mosquito Culex pipiens, and pupal diapause in the flesh fly Sarcophaga crassipalpis provide strong evidence that insulin signaling is also an important component of the regulatory pathway leading to the diapause phenotype. Insects produce many different insulin-like peptides (ILPs), and not all are involved in the diapause response; ILP-1 appears to be the one most closely linked to diapause in $C$. pipiens. Many steps in the pathway leading from perception of daylength (the primary environmental cue used to program diapause) to generation of the diapause phenotype remain unknown, but the role for insulin signaling in mosquito diapause appears to be upstream of $\mathrm{JH}$, as evidenced by the fact that application of exogenous $\mathrm{JH}$ can rescue the effects of knocking down expression of ILP-1 or the Insulin Receptor. Fat accumulation, enhancement of stress tolerance, and other features of the diapause phenotype are likely linked to the insulin pathway through the action of a key transcription factor, FOXO. This review highlights many parallels for the role of insulin signaling as a regulator in insect diapause and dauer formation in the nematode Caenorhabditis elegans.

Keywords: diapause, dauer, insulin signaling, FOXO, Culex pipiens

\section{INTRODUCTION}

Diapause is a form of dormancy used widely by insects to survive adverse seasons. Unlike quiescence, defined as an immediate response to an unfavorable environmental stress, diapause is an anticipated, hormonally-regulated developmental arrest, frequently programmed by photoperiod. Within temperate zones, insects are temporally limited to just a few months of active development, while the remaining months are spent in diapause. Depending on the species, insect diapause can occur in embryos (e.g., the commercial silkmoth Bombyx mori), larvae (e.g., southwestern corn borer Diatraea grandiosella), pupae (e.g., flesh fly Sarcophaga crassipalpis) or adults (e.g., mosquito Culex pipiens). Among species in temperate zones, an overwintering diapause is most common, but a summer diapause can also occur (Masaki, 1980), and diapause is also well-documented among tropical species (Denlinger, 1986). In temperate zones the shortening day lengths and declining temperatures of late summer and early autumn provide the dominant environmental cues signaling the advent of winter (Tauber et al., 1986; Kostal and Denlinger, 2011), cues that set into motion a series of preparatory steps for successful overwintering.

The environmental cues used to program diapause are frequently received long before the actual inception of diapause. Depending on the species, the photoperiodic signals are received either through the eyes or directly by light-sensitive cells within the brain (Goto et al., 2010; Numata and Udaka, 2010). Most evidence suggests that the circadian clock is involved in distinguishing short from long days (Saunders, 2012; Goto, 2013; Meuti and Denlinger, 2013). The transduction pathway for photoperiodic stimuli engages neurons in the pars intercerebralis, pars lateralis and other domains within the brain (Shiga and Numata, 2000; Shimokawa et al., 2008) that release neuropeptides or growth factors into neighboring or remote cells to regulate development. Among the targets of these neuropeptides are endocrine glands such as the corpora cardiaca, the corpora allata and the prothoracic gland, organs that in turn synthesize and release hormones including juvenile hormones, ecdysteroids, adipokinetic hormone, as well as additional neuropeptides that impact insect diapause.

A functional module approach is a helpful way to view the diapause mechanism (Emerson et al., 2009; Bradshaw and Holzapfel, 2010). Three candidate modules are proposed: an input module that includes the functional timekeeping mechanism, an intermediate module linking photoperiodism to hormonal events, and an output module that includes the physiological responses. Modularity of this sort has been commonly invoked to interpret genetic mechanisms of embryonic development such as pattern formation and differentiation (Raff, 1996). Key components in a module are signaling cascades such as hedgehog, transforming growth factor (TGF- $\beta$ ) and insulin signaling (Cohen, 2003; Dupont and Holzenberger, 2003; Logan and Nusse, 2004; Bray, 2006; Kitisin et al., 2007). If we consider diapause as an alternative developmental program with separate functional modules, the application of this concept may be useful for dissecting molecular mechanisms of diapause programs.

Several recent reviews discuss regulatory features of diapause such as molecular regulation (Denlinger, 2002; Robich 
and Denlinger, 2005; Macrae, 2010; Williams et al., 2010), hormonal control (Denlinger et al., 2012), the circadian clock and photoperiodism (Goto et al., 2010; Saunders, 2010; Kostal, 2011), and energy utilization (Hahn and Denlinger, 2007, 2011). One unifying theme for diapause in diverse species may be insulin signaling (Tatar and Yin, 2001; Williams et al., 2006; Sim and Denlinger, 2008, 2009a). This signaling pathway has been linked to diverse features of the diapause phenotype including arrested reproduction, extended lifespan, suppressed metabolism, fat hypertrophy and enhanced stress tolerance. Dauer formation in the nematode Caenorhabditis elegans (Figure 1) offers many parallels to insect diapause, including a role for insulin signaling, thus the comprehensive understanding of the molecular basis for dauer formation (Gottlieb and Ruvkun, 1994; Kimura et al., 1997; Apfeld and Kenyon, 1998) provides valuable insights for exploring general patterns of developmental arrest in invertebrate systems. The goal of this review is to summarize evidence linking insulin signaling to insect diapause and to thus create a foundation for developing a comprehensive view of the role of this pathway in shaping the complex diapause phenotype.

\section{COMPONENTS OF THE INSULIN SIGNALING PATHWAY}

Insulin signaling has been implicated as a regulator of diapause by observing the effects of this pathway on developmental and metabolic suppression (Apfeld and Kenyon, 1998; Tatar et al., 2001; Hahn and Denlinger, 2007; Sim and Denlinger, 2008; Ragland et al., 2010; Williams et al., 2010) and by observing naturally segregating variation of PI3K, a member of the insulin signaling pathway, in association with adult reproductive diapause in Drosophila melanogaster (Williams et al., 2006).

Seven genes encode insulin-like peptides in Drosophila (Brogiolo et al., 2001). All of these peptides have a domain structure that produces two chains, resulting in active dimer formation (Leevers, 2001). Drosophila insulin receptor (receptor tyrosine kinases) shares sequence similarity with human insulin receptor and can be activated by insulin (Fernandez et al., 1995; Chen et al., 1996). Activated receptor tyrosine kinases (RTKs) activate phosphatidylinositol 3-kinase (PI3K) through direct binding or through tyrosine phosphorylation of scaffolding adaptors, such as IRS1, which then bind and activate PI3K. PI3K phosphorylates phosphatidylinositol-4,5-bisphosphate $\left(\mathrm{PIP}_{2}\right)$ to generate phosphatidylinositol-3,4,5-trisphosphate $\left(\mathrm{PIP}_{3}\right)$ (Britton et al., 2002). In the end, PI3K targets two intracellular signaling proteins, Akt (also known as Protein Kinase B, PKB) and 3-phophoinositide-dependent protein kinase-1 (PDK-1); phosphorylation at serine and threonine residues activates Akt and PDK-1 (Taniguchi et al., 2006).

Akt plays a key role in multiple cellular processes including glucose metabolism, apoptosis, cell proliferation, transcription and cell migration (Hanada et al., 2004; Fayard et al., 2005). These various cellular processes are mediated by transcriptional factors and kinases which are activated by Akt phosphorylation. The downstream molecules of Akt include forkhead of transcriptional factors (FOXs), glycogen synthase kinase-3 (GSK-3), tuberous sclerosis complex (TSC1/2) and Rab-GTPase-activating protein (Rab-GAP) (Frame et al., 2001; Harris and Lawrence, 2003; Junger et al., 2003; Sano et al., 2003). In addition, a

\section{Nematode (Caenorhabditis elegans) Mosquito (Culex pipiens)}

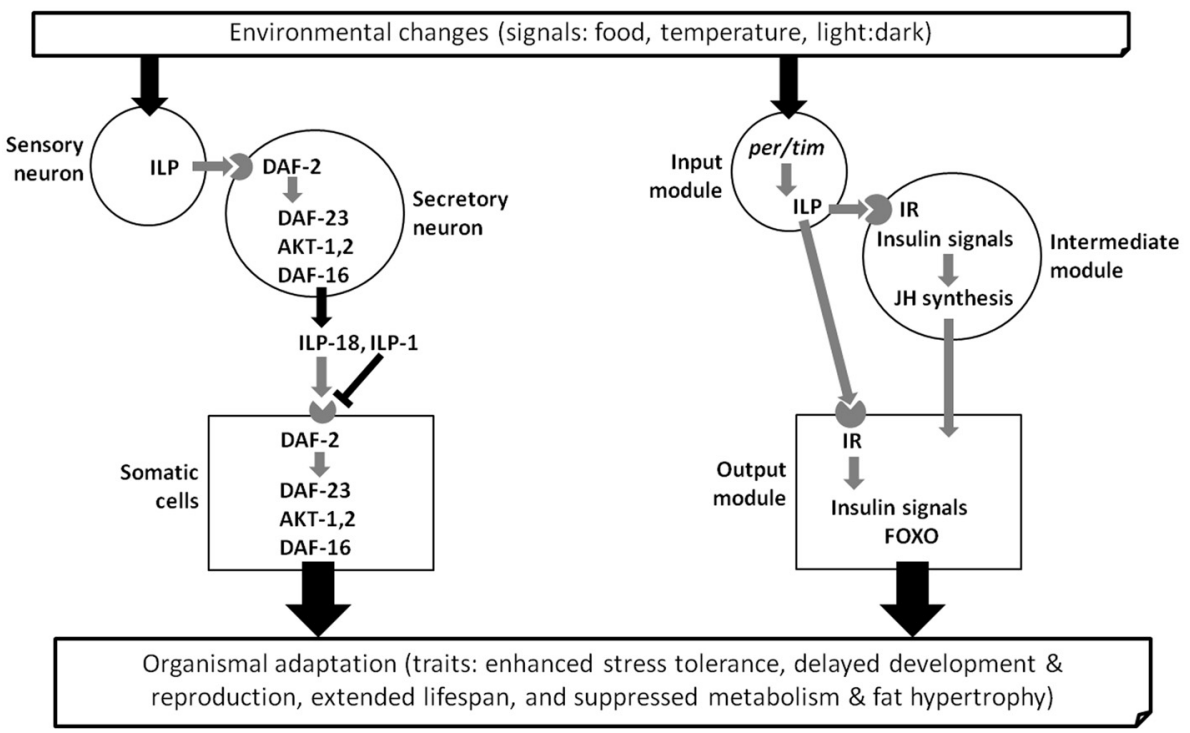

FIGURE 1| Three conceptual modules (input, intermediate and output) that influence dauer larva formation in the nematode Caenorhabditis elegans and adult diapause of the mosquito Culex pipiens, based on references in the text. Gene activation (Black) and deactivation (Gray). Insulin-like peptide, ILP; DAF-2, insulin receptor
(IR); DAF-23, phosphoinoitide 3-kinase; Akt, protein kinase B; DAF-16, forkhead transcription factor (FOXO); per/tim, core genes of molecular clock system; JH, juvenile hormone. The mosquito FOXO and insulin receptor (IR) are homologs of nematode DAF-16 and DAF-2, respectively. 
number of upstream proteins regulate Akt; these include protein phosphatase 2A (PP2A), wideborst (Wdb), and a PH-domain leucine-rich repeat protein phosphatase (PHLPP) (Du et al., 2003; Vereshchagina et al., 2008).

Several proteins are involved in regulation of the insulin receptor and thus influence intracellular signaling components in the insulin signaling pathway. Protein Tyrosine Phosphatase 1B dephosphorylates active insulin receptor (Elchebly et al., 1999), while suppressors of cytokine signaling (SOCS)-1 and SOCS-3 can bind insulin receptor substrate, and attenuate insulin signals (Ueki et al., 2004). Other molecules including extracellular-signal-regulated kinase (ERK), Jun- $\mathrm{N}$-terminal kinases, and kinase $\mathrm{S} 6$ attenuate the activity of insulin receptor (Miller et al., 1996; Bouzakri et al., 2003; Harrington et al., 2004). Phosphatase and tensin homolog (PTEN) can also inactivate $\mathrm{PIP}_{3}$, a midpoint in the insulin signaling pathway (Goberdhan et al., 1999). Comprehensive reviews describe details of structure, signaling, function of insulin-like peptides, as well as other components of the insulin signaling pathway (Luckhart and Riehle, 2007; Antonova et al., 2012).

One outstanding question that remains is how input from the photoperiodic clock is linked to the insulin signaling pathway. Several candidate neuropeptides could serve as intermediaries. For example, Pigment Dispersing Factor (PDF) appears to be an output molecule of the circadian clock system in several insects and has been extensively studied in D. melangaster (Meelkop et al., 2011). Additional neuropeptides in flies, short neuropeptide $F$ (sNPF), corazonin (CRZ) and drosulfakinins (DSKs), function in regulating insulin production, and thus could also serve an intermediary role. Some insulin-producing cells (IPCs) in the fly brain also coexpress receptors of both sNPF and CRZ neuropeptides, as well as the ligand for DSKs (Kapan et al., 2012; Soderberg et al., 2012). In these studies, knockdown of either sNPF or DSK decreases transcription of ILPs in the brain, suggesting a regulatory action of these two neuropeptides on IPCs. In Rhodnius prolixus, levels of prothoracicotrophic hormone (PTTH) oscillate in a circadian manner, suggesting a possible link between PTTH and clock functions as well (Vafopoulou et al., 2007, 2012). Yet, links between these neuropeptides, insulin signaling, and insect diapause remain to be determined.

\section{CELL CYCLE AND DEVELOPMENTAL REGULATION}

Arrest of the cell cycle and development are key characteristics of diapause. Pupal diapause in the flesh fly involves a G0/G1 cell cycle arrest that appears to be controlled by down regulation of proliferating cell nuclear antigen (Tammariello and Denlinger, 1998), a gene that controls the cell cycle by direct interaction with the cyclin/cdk complex (Watanabe et al., 1998). FOXO proteins have known roles in inducing cell cycle arrest. For example, in dauer larvae of Caenorhabditis elegans a FOXO homolog induces a G0/G1 cell cycle arrest through induction of Cip/Kip inhibitor, Cki-1 (Boxem and Van Den Heuvel, 2001). A similar role for FOXO is evident in Drosophila (Kramer et al., 2003), in which activated dFOXO promotes a G1 cell cycle arrest.

Drosophila females reared under low temperature and short daylength enter an adult reproductive diapause characterized by arrest of ovarian development in the previtellogenic stage, while non-diapausing females initiate vitellogenesis and complete ovarian development (Tatar et al., 2001). Development of Drosophila ovaries is regulated by an insulin signal in germ cells; dILPs specifically control the G2 phase of germ cell cycle via PI3K and dFOXO (LeFever and Drummond-Barbosa, 2005; Hsu et al., 2008). Regulation of ovarian development by insulin signaling is not limited to Drosophila but is also evident in the mosquito Culex pipiens. The insulin signal/FOXO pathway is central to initiation of the diapause program, including ovarian development arrest. A "diapause-like" ovarian arrest can be simulated in nondiapausing females by knocking down the insulin receptor (InR) using RNAi; this knock-down effect can be reversed with application of juvenile hormone, an endocrine stimulant well-known to terminate diapause in this species (Sim and Denlinger, 2008). Insulin-like peptide 1 (ILP-1) is the ILP most likely implicated in the diapause response of Cx. pipiens (Sim and Denlinger, 2009a).

In C. elegans, low food levels prompt synthesis of high levels of dauer pheromone, which in turn lead to dauer formation, rather than reproductive growth (Golden and Riddle, 1982, 1984). These environmental cues initially alter insulin signaling by regulating insulin-like peptide synthesis and secretion in specific subsets of sensory neurons. C. elegans has only a single insulin receptor (daf-2), but it has genes encoding 40 putative insulin-like peptides (Flatt et al., 2008a). Daf-2 is implicated in many genetically separable processes, including the dauer decision, lifespan control, and reproductive timing (Flatt et al., 2008b; Lee et al., 2008). Mutants with reduced daf- 2 activity enter the dauer state, while increased insulin signaling promotes germ line proliferation, resulting in an increase of germ line stem cells. Many of the ILPs are expressed in sensory neurons and interneurons, where they encode distinct environmental information to regulate initiation and termination of dauer formation. For example, ILP-1(ins-1) induces dauer arrest under low food levels, and under favorable food conditions, daf-28 (insulin-like peptide) inhibits dauer arrest, whereas ILP-6 (ins-6) promotes the transition from the dauer state to normal reproductive growth (Cornils et al., 2011).

The finding that ILPs in C. elegans encode environmental cues used to regulate physiology also reflects what is found in insects, such as the fly $D$. melanogaster and the mosquito C. pipiens. D. melanogaster has genes encoding 7 ILPs, and as in C. elegans, the ILPs are expressed in different sensory neurons and interneurons. Interestingly, some of these neuronally-expressed ILPs (dilp-2, -3, -5) have been proposed to regulate growth and metabolism (Ikeya et al., 2002; Broughton et al., 2008; Zhang et al., 2009). We thus argue that insulin signals are likely used as mediators of a wide range of environmental cues, including those involved in regulating diverse forms of developmental arrest (Figure 1).

\section{LIFESPAN EXTENSION}

Genetic studies using the nematode C. elegans and the fruit fly D. melanogaster have identified several genes involved in extending lifespan. Work on the dauer stage of C. elegans is at the forefront of such research. Genome-wide RNAi screens identified key functional groups in the C. elegans insulin signaling pathway that contribute to lifespan extension (Hamilton et al., 2005). Most mutants with reduced insulin-like signaling have both dauer and 
extended lifespan responses, but in some cases there are distinct differences when and where insulin/FOXO signals are activated. Most studies on daf-2 suggest it functions within the nervous system to regulate lifespan as well as dauer arrest (Kimura et al., 1997; Apfeld and Kenyon, 1998). Yet, several studies on the target of insulin signaling, daf-16 (aka forkhead of transcriptional factor FOXO), suggest that dauer arrest and lifespan are regulated by FOXO activity in a different way: FOXO within the nervous system has a stronger influence on dauer arrest than on lifespan, whereas intestinal FOXO plays a greater role in regulating lifespan than in regulating dauer arrest (Libina et al., 2003). Thus, FOXO activation in different tissues may have distinct phenotypic consequences. Furthermore, insulin signaling during larval development regulates dauer arrest without significantly impacting lifespan, whereas insulin-like signaling during adulthood regulates lifespan (Dillin et al., 2002). Daf-2 is thought to activate a conserved PI-3 kinase signaling pathway that affects lifespan, at least in part by regulating nuclear localization of daf-16 (FOXO). This transcription factor, FOXO, appears to extend lifespan by activating its downstream genes products such as superoxide dismutase, metallothionin, catalase, glutathione S-transferase, small heat shock proteins, and apolipoprotein (Vanfleteren and De Vreese, 1995; Honda and Honda, 1999; Barsyte et al., 2001; Sun et al., 2002; Walker and Lithgow, 2003).

Diapause incidence in $D$. melanogaster varies among populations (Schmidt et al., 2005; Williams et al., 2006). A transgenic study of Dp110 (phosphoinositide 3-kinase), a member of the insulin signaling pathway, supports the view that this gene, and hence the insulin signaling pathway, plays an important role in induction of reproductive diapause (Williams et al., 2006). Knock-down of genes encoding insulin-like peptides, insulin receptor and CHICO (IRS), and overexpression of the downstream transcription factor $\mathrm{dFOXO}$, as well as inhibitor studies using the $\mathrm{PIP}_{3}$ inhibitor PTEN, all reduce insulin signaling and subsequently extend lifespan (Clancy et al., 2001; Giannakou et al., 2004; Hwangbo et al., 2004; Giannakou and Partridge, 2007; Lee et al., 2008; Demontis and Perrimon, 2010; Gronke et al., 2010). Likewise, induction of the tuberous sclerosis complex (TSC1/2), kinase S6, the dFOXO regulated histone deacetylase Sir2, and the insulin signal suppressing pathway Jun-N-terminal kinase (JNK) extend lifespan (Kapahi et al., 2004; Partridge et al., 2005; Wang et al., 2005).

Furthermore, insulin signals appear to be a regulator of juvenile hormone synthesis (Flatt et al., 2005; Tu et al., 2005). In Drosophila, insulin receptors are present in the corpora allata (CA), the glands that synthesize $\mathrm{JH}$ (Belgacem and Martin, 2006), and suppression of the insulin signal correlates with low $\mathrm{JH}$ production (Tatar and Yin, 2001; Tu et al., 2005). Knockdown of the insulin receptor in the CA concurrently suppresses the gene encoding 3-hydroxy-3-methylglutargyl CoA Reductase (HMGCR), a key enzyme in JH synthesis (Belgacem and Martin, 2007). The subsequent shut-down of JH synthesis is a key signaling event triggering the onset of adult reproductive diapause in many insects (Denlinger et al., 2005), including D. melanogaster, the mosquito $C x$. pipiens and the butterfly Danaus plexippus (Herman, 1981; Herman and Tatar, 2001; Sim and Denlinger, 2008). D. melanogaster selected to survive a high dose of JH analog overcame lifespan reduction when compared to flies not receiving JH (Flatt and Kawecki, 2007). These lines of evidence suggest that $\mathrm{JH}$ is involved in the trade-off between reproduction and extended lifespan through the insulin signaling pathway.

\section{SUPPRESSED METABOLISM AND FAT HYPERTROPHY}

At the initiation of diapause, metabolic processes are coordinately downregulated, thus enabling the overwintering insect to economically utilize its energy reserves, but in addition, this metabolic downregulation helps to minimize deficiencies in cellular processes that can cause cell death (Hand et al., 2011). Diapausing insects remain hypometabolic even after temperatures revert to conditions favorable for development. However, certain metabolic genes involved in the accumulation of energy reserves are highly upregulated, especially during the preparatory period of diapause. This energy storage is critical not only for surviving prolonged periods of developmental arrest but also for maximizing reproductive success once development resumes (Hahn and Denlinger, 2007). Carbohydrate sources such as nectar and rotten fruit are critical carbohydrate sources used for increasing energy reserves in adult diapausing females of the mosquito Cx. pipiens, the butterfly Danaus plexippus, and some other diapausing insects (Alonsomejia et al., 1997; Robich and Denlinger, 2005; Reynolds et al., 2012). We generated transcript profiles of thirty-two fat-related genes during diapause in the mosquito $C x$. pipiens (Sim and Denlinger, 2009b), and among the genes upregulated in early diapause were fatty acid synthase- $1,-3$, and fatty acid binding protein, genes that contribute to accumulation of triacylglycerides in the fat body. This result is consistent with the observation that this mosquito switches from blood feeding to sugar feeding as a component of the diapause program and more than doubles its lipid reserves compared with females programmed for continuous development. When we knocked down foxo transcript by injection of dsRNA into these diapausing mosquitoes, we observed an immediate halt in the accumulation of lipid reserves (Sim and Denlinger, 2008). FOXO is normally activated by suppression of insulin signaling; thus FOXO may be involved in increasing transcript levels of genes involved in fatty acid synthesis, as observed in newly-emerged diapausing females. A transcriptome analysis of the Asian tiger mosquito, Aedes albopictus, also suggests the importance of FOXO during early diapause (Poelchau et al., 2011).

Insulin signaling and its target FOXO are implicated as a major regulator of diapause through effects on metabolic suppression, fat hypertrophy, and growth control (Puig et al., 2003; Williams et al., 2006; Hahn and Denlinger, 2007; Sim and Denlinger, 2009a,b; Ragland et al., 2010). A transcriptome analysis of diapause termination in the apple maggot fly, Rhagoletis pomonella, reveals the importance of the TOR signaling pathway, a pathway that interacts with insulin signaling (Ragland et al., 2011). TSC1 and TSC2, negative regulators of TOR signals and regulators of cell growth, were significantly upregulated in late diapause. FOXO and TOR pathways are both linked to insulin signaling and offer links for integrating metabolic and growth responses.

Among the Drosophila insulin-like peptides, ligands 1-5 are predicted to be closely related to mammalian insulin, while ligands 6 and 7 are more similar to IGF-1 and relaxin, respectively 
(Brogiolo et al., 2001). Four of these insulin-like peptides, 1, 2, 3, and 5 are expressed in insulin-producing cells (IPCs) in the brain (Cao and Brown, 2001; Ikeya et al., 2002; Rulifson et al., 2002), and loss of insulin-like peptide-producing cells or mutations in the gene for Drosophila insulin receptor (dInR) or CHICO results in a significant increase in triacylglycerides (Bohni et al., 1999; Tatar et al., 2001; Broughton et al., 2005). By contrast, insulin is a positive regulator of fat cell mass, acting through changes in both cell number and lipid storage (Diangelo and Birnbaum, 2009). This evidence suggests that, unlike in mammals, different insect ILP may be involved in regulating distinct physiological processes such as energy metabolism, fat cell proliferation, lipid storage and other key traits for survival. Thus, it will be important to know when and where particular insulin-like peptides are suppressed or activated, and how the insulin-like peptides generate the increased fat cell mass and lipid storage in diapausing insects.

\section{ENHANCED STRESS TOLERANCE}

Diapausing insects are particularly well-adapted to survive low temperatures and other forms of environmental stress (Denlinger and Lee, 2010). Cold hardiness is frequently a component of the diapause program but is sometimes acquired after the onset of diapause, in direct response to low temperature (Denlinger, 1991). A variety of molecular mechanisms are used to either avoid or survive freezing (Michaud and Denlinger, 2006, 2007; Khani and Moharramipour, 2010; Vesala and Hoikkala, 2011). Suppression of the insulin signal appears to induce physiological responses promoting resistance to low temperature, oxidative stress, and pathogenic infections (Clancy et al., 2001; Broughton et al., 2005; Zhang et al., 2009; Felix et al., 2012). In C. elegans, dauer larvae differ from non-dauer larvae in aspects of metabolism related to cold tolerance. Genes involved in trehalose synthesis are upregulated in daf-2 (insulin receptor) mutants and dauers (Wang and Kim, 2003; McElwee et al., 2006; Shmookler Reis et al., 2011). Fatty acid desaturase genes are essential for cold tolerance in many animals, an effect promoted by the preservation of membrane fluidity at sub-zero temperatures (Gracey et al., 2004; Brock et al., 2007; Murray et al., 2007). Cold tolerance in dauers is enhanced by the overlapping effect of genes encoding fatty acid desaturase, targeted by insulin signal/FOXO, and genes involved in the cold-induced stress response (Savory et al., 2011).

Drosophila FOXO has a critical role in the systemic regulation of antioxidant enzymes, a response that acts through the insulin/FOXO signaling pathway in insulin-producing cells (IPCs) (Kops et al., 2002b; Hwangbo et al., 2004). FOXO activation subsequently increases stress tolerance through upregulation of superoxide dismutases (Kops et al., 2002a). This genetic regulation of antioxidant enzymes by FOXO is also noted in C. elegans (Vanfleteren and De Vreese, 1995) and the mosquito Cx. pipiens (Sim and Denlinger, 2011). Dauer worms and diapausing mosquitoes increase expression of the protective enzymes superoxide dismutase and catalase. In addition, several genomewide studies indicate that detoxification/stress response genes are among the most common group of genes regulated by the insulin/FOXO signaling pathway (Murphy et al., 2003; Oh et al., 2006; Gershman et al., 2007).
The insulin signaling pathway also plays a critical role in regulation of innate immunity and lifespan in many insects (Luckhart and Riehle, 2007). However, there is a dichotomy in the functional role of insulin signals in activation of the immune response. For example, in the mosquito Anopheles stephensi, increased $\mathrm{Akt} / \mathrm{PKB}$ signaling in the midgut significantly reduces malaria parasite development compared to control mosquitoes (CorbyHarris et al., 2010). The brain of the mosquito Aedes aegypti releases insulin-like peptides (ILPs) in response to a blood meal. In turn, the insulin signal induces hemocyte (immune cells) production, which serve as the first line of defense against pathogenic infections (Castillo et al., 2011). By contrast, in C. elegans, insulin signals are linked to both innate immunity and extended lifespan. The loss of function of insulin receptor (daf-2) results in decreased insulin signaling and enhanced resistance to pathogenic bacterial infection (Garsin et al., 2003). When forkhead transcription factor (daf-16), which is negatively regulated by the insulin signaling pathway in C. elegans, is suppressed the worms exhibit increased susceptibility to infection by pathogenic bacteria. Similar results were found in the fly D. melanogaster, in which there is a link between the Toll signaling pathway, the pathway that activates the innate immune response, and the insulin signaling pathway (Diangelo et al., 2009). These lines of evidence suggest that insulin/FOXO signaling in diapausing insects may be linked to induction of immune effectors that enhance resistance to pathogenic infection.

\section{FUTURE DIRECTION}

The evidence we present links the insulin/FOXO signaling pathway to insect diapause characteristics including cell cycle arrest, developmental arrest, extended lifespan, suppressed metabolism, fat hypertrophy, and enhanced stress tolerance. Although relatively few insect species have been examined, involvement of this pathway may emerge as one of the unifying themes of insect diapause. In life-history studies, the insulin/FOXO signaling pathway appears to also regulate growth, reproduction, and lifespan in numerous species including flies, worms and mosquitoes. Phenotypic plasticity observed in life-history traits provides insights for understanding relationships among diapause characteristics. Similar phenotypic plasticity of fitness factors is evident in diapause, i.e., trade-offs between/among diapause characteristics. For example, in adult reproductive diapause, extended lifespan is frequently coupled with arrested ovarian development and suppressed metabolic rate. Since insulin signaling plays a role in phenotypic plasticity among fitness factors, we propose that the insulin signal is a key regulator among diapause characteristics including suppressed growth and metabolism, enhanced stress tolerance, and extended lifespan. This idea raises several new questions. First, what is the nature and extent of the linkages among modules through insulin signals? Second, how are changes in insulin signals within one module coordinated with others, and what are the mechanisms that promote systemic changes? The answers to these questions are not simple, but recent advances in genomics and functional genetics provide new opportunities for testing hypotheses of this nature. Hopefully, such experiments will enable us to pinpoint the molecular mechanisms of phenotypic plasticity associated with insect diapause. 
Several lines of evidence support our proposition. First, recent studies found that insulin signals can act locally as well as systemically in the fruit fly D. melanogaster. The glia provide local signals necessary for activation of neighboring neuroblasts, and interestingly the glia also produce insulin-like peptides (ILPs) that respond to signals from the fat body by binding to receptors on larval neuroblasts (Chell and Brand, 2010; Sousa-Nunes et al., 2011). Considering the fact that the brain, endocrine organs (corpora cardiac, corpora allata, prothoracic gland), and fat body are all key organs essential to the diapause response, the presence of a systemic signaling system operating among these organs is likely to offer a conduit for cross-talk that may be critical for implementing and coordinating a successful diapause program (Xu et al., 2012). With the insulin signaling pathway being involved in so many aspects of the diapause phenotype, the local and systemic signals from different insulin-like peptides are promising candidates to explain molecular mechanisms used to generate this phenotype.

Secondly, modularity is a suitable model for viewing the complicated molecular mechanisms of diapause. Circadian clock oscillations (input module) are certainly functioning in the insect brain and likely contribute to photoperiodism (Ito et al., 2008; Ikeno et al., 2010). Interestingly, the clock genes have linkages to insulin signaling (Allen, 2007; Zheng and Sehgal, 2010). Diapause incidence in Drosophila is elevated when PI3-kinase, an insulin-regulated gene, is upregulated and is lowered when this gene is downregulated (Williams et al., 2006). This connection most likely acts through Susi, an inhibitor of insulin-regulated PI3-kinase. Susi shows a circadian pattern of expression that is

\section{REFERENCES}

Allen, M. J. (2007). What makes a fly enter diapause. Fly (Austin) 1, 307-310.

Alonsomejia, A., Rendonsalinas, E., Montesinospatino, E., and Brower, L. P. (1997). Use of lipid reserves by monarch butterflies overwintering in Mexico: implications for conservation. Ecol. Appl. 7, 934-947. doi: 10.1890/1051-0761(1997)007[0934: UOLRBM]2.0.CO;2

Antonova, Y., Arik, A. J., Moore, W., Riehle, M. A., and Brown, M. R. (2012). "Insulin-like peptides: structure, signaling, and function," in Insect Endocrinology, ed L. I. Gilbert (San Diego, CA: Academic Press), 63-92.

Apfeld, J., and Kenyon, C. (1998). Cell nonautonomy of $C$. elegans daf-2 function in the regulation of diapause and life span. Cell 95, 199-210. doi: 10.1016/S00928674(00)81751-1

Barsyte, D., Lovejoy, D. A., and Lithgow, G. J. (2001). Longevity and heavy metal resistance in daf-2 and age-1 long-lived mutants of Caenorhabditis elegans. FASEB J. 15, 627-634. doi: 10.1096/fj.99-0966com
Belgacem, Y. H., and Martin, J. R. (2006). Disruption of insulin pathways alters trehalose level and abolishes sexual dimorphism in locomotor activity in Drosophila. J. Neurobiol. 66, 19-32. doi: 10.1002/neu.20193

Belgacem, Y. H., and Martin, J. R. (2007). Hmgcr in the corpus allatum controls sexual dimorphism of locomotor activity and body size via the insulin pathway in Drosophila. PLoS ONE 2:e187. doi: 10.1371/journal.pone. 0000187

Bohni, R., Riesgo-Escovar, J., Oldham, S., Brogiolo, W., Stocker, H., Andruss, B. F., et al. (1999). Autonomous control of cell and organ size by CHICO, a Drosophila homolog of vertebrate IRS1-4. Cell 97, 865-875. doi: 10.1016/S0092-8674(00)80799-0

Bouzakri, K., Roques, M., Gual, P., Espinosa, S., Guebre-Egziabher, F., Riou, J. P., et al. (2003). Reduced activation of phosphatidylinositol3 kinase and increased serine 636 phosphorylation of insulin receptor substrate-1 in primary culture of skeletal muscle cells from patients with type 2 diabetes.

high at night and low during the day (Claridge-Chang et al., 2001; McDonald et al., 2001; Wittwer et al., 2005). We suggest that insulin signaling is suppressed by long nightlengths (short daylengths), which in turn suppresses juvenile hormone synthesis within the corpora allata (intermediate module) (Hardie et al., 1985; Tatar et al., 2001; Tu et al., 2005). The fat body (output module) is crucial to important physiological functions including nutrient sensing, lipid storage, and endocrine signaling to the brain and reproductive organs. Additionally, the fat body is the nexus for lipid storage, arrested reproductive development, and induced stress tolerance during diapause. Insulin/FOXO appears to coordinate, or at least be involved in, the physiological responses during each module of adult reproductive diapause (Sim and Denlinger, 2008, 2009a, 2011, 2013). However, we still lack details and insight into how insulin signals affect each module of diapause at both local and systemic levels and to what extent insulin/Foxo signals are involved in diapauses of different developmental stages. Diapause appears to have evolved multiple times in insect lineages, thus we can very well-expect species variation in how this signaling pathway is exploited for regulating diapause in different species. The exciting prospect is that the pervasive influence of insulin signaling offers connections to insect diapause at many levels, from connections to photoperiodism through to the downstream generation of many of the phenotypic characteristics of the diapause state.

\section{ACKNOWLEDGMENTS}

This work was supported in part by National Institutes of Health grant 2R56-AI058279.

Diabetes 52, 1319-1325. doi: 10.2337/diabetes.52.6.1319

Boxem, M., and Van Den Heuvel, S. (2001). lin-35 Rb and cki-1 Cip/Kip cooperate in developmental regulation of G1 progression in C. elegans. Development 128, 4349-4359.

Bradshaw, W. E., and Holzapfel, C. M. (2010). Light, time, and the physiology of biotic response to rapid climate change in animals. Annu. Rev. Physiol. 72, 147-166. doi: 10.1146/annurev-physiol021909-135837

Bray, S. J. (2006). Notch signalling: a simple pathway becomes complex. Nat. Rev. Mol. Cell Biol. 7, 678-689. doi: 10.1038/nrm2009

Britton, J. S., Lockwood, W. K., Li, L., Cohen, S. M., and Edgar, B. A. (2002). Drosophila's insulin/PI3kinase pathway coordinates cellular metabolism with nutritional conditions. Dev. Cell 2, 239-249. doi: $\quad$ 10.1016/S1534-5807(02) 00117-X

Brock, T. J., Browse, J., and Watts, J. L. (2007). Fatty acid desaturation and the regulation of adiposity in Caenorhabditis elegans. Genetics 176, 865-875. doi: 10.1534/genetics. 107.071860
Brogiolo, W., Stocker, H., Ikeya, T., Rintelen, F., Fernandez, R., and Hafen, E. (2001). An evolutionarily conserved function of the Drosophila insulin receptor and insulin-like peptides in growth control. Curr. Biol. 11, 213-221. doi: 10.1016/S0960-9822(01)00068-9

Broughton, S., Alic, N., Slack, C., Bass, T., Ikeya, T., Vinti, G., et al. (2008). Reduction of DILP2 in Drosophila triages a metabolic phenotype from lifespan revealing redundancy and compensation among DILPs. PLoS ONE 3:e3721. doi: 10.1371/journal.pone. 0003721

Broughton, S. J., Piper, M. D., Ikeya, T., Bass, T. M., Jacobson, J., Driege, Y., et al. (2005). Longer lifespan, altered metabolism, and stress resistance in Drosophila from ablation of cells making insulinlike ligands. Proc. Natl. Acad. Sci. U.S.A. 102, 3105-3110. doi: 10.1073/pnas.0405775102

Cao, C., and Brown, M. R. (2001). Localization of an insulin-like peptide in brains of two flies. Cell Tissue Res. 304, 317-321. doi: 10.1007/s004410100367

Castillo, J., Brown, M. R., and Strand, M. R. (2011). Blood feeding and 
insulin-like peptide 3 stimulate proliferation of hemocytes in the mosquito Aedes aegypti. PLoS Pathog. 7:e1002274. doi: 10.1371/journal.ppat.1002274

Chell, J. M., and Brand, A. H. (2010). Nutrition-responsive glia control exit of neural stem cells from quiescence. Cell 143, 1161-1173. doi: 10.1016/j.cell.2010.12.007

Chen, C., Jack, J., and Garofalo, R. S. (1996). The Drosophila insulin receptor is required for normal growth. Endocrinology 137, 846-856. doi: 10.1210/en.137.3.846

Clancy, D. J., Gems, D., Harshman, L. G., Oldham, S., Stocker, H., Hafen, E., et al. (2001). Extension of life-span by loss of CHICO, a Drosophila insulin receptor substrate protein. Science 292, 104-106. doi: 10.1126/science.1057991

Claridge-Chang, A., Wijnen, H., Naef, F., Boothroyd, C., Rajewsky, N., and Young, M. W. (2001). Circadian regulation of gene expression systems in the Drosophila head. Neuron 32, 657-671. doi: 10.1016/S08966273(01)00515-3

Cohen, M. M. Jr. (2003). The hedgehog signaling network. Am. J. Med. Genet. A 123A, 5-28. doi: 10.1002/ajmg.a.20495

Corby-Harris, V., Drexler, A., Watkins De Jong, L., Antonova, Y., Pakpour, N., Ziegler, R., et al. (2010). Activation of Akt signaling reduces the prevalence and intensity of malaria parasite infection and lifespan in Anopheles stephensi mosquitoes. PLoS Pathog. 6:e1001003. doi: 10.1371/annotation/738ac91f-8c414bf5-9a39-bddf0b777a89

Cornils, A., Gloeck, M., Chen, Z., Zhang, Y., and Alcedo, J. (2011). Specific insulin-like peptides encode sensory information to regulate distinct developmental processes. Development 138, 1183-1193. doi: 10.1242/dev.060905

Demontis, F., and Perrimon, N. (2010). FOXO/4E-BP signaling in Drosophila muscles regulates organism-wide proteostasis during aging. Cell 143, 813-825. doi: 10.1016/j.cell.2010.10.007

Denlinger, D. L. (1986). Dormancy in tropical insects. Annu. Rev. Entomol. 31, 239-264. doi: 10.1146/annurev. en.31.010186.001323

Denlinger, D. L. (1991). "Relationship between cold-hardiness and diapause," in Insects at Low Temperature, eds R. E. Lee and D. L. Denlinger (New York, NY: Chapman and Hall), 174-198.

Denlinger, D. L. (2002). Regulation of diapause. Annu. Rev. Entomol. 47,
93-122. doi: 10.1146/annurev.ento. 47.091201.145137

Denlinger, D. L., and Lee, R. E. (2010). Low Temperature Biology of Insects, Cambridge: Cambridge University Press. doi: 10.1017/СBO9780511675997

Denlinger, D. L., Yocum, G. D., and Rinehart, J. P. (2005). "Hormonal control of diapause," in Comprehensive Molecular Insect Science, eds L. I. Gilbert, K. Iatrou, and S. S. Gill (Amsterdam: Elsevier), 615-650.

Denlinger, D. L., Yocum, G. D., and Rinehart, J. P. (2012). "Hormonal control of diapause," in Insect Endocrinology, ed L. I. Gilbert (Amsterdam: Elsevier), 430-463.

Diangelo, J. R., and Birnbaum, M. J. (2009). Regulation of fat cell mass by insulin in Drosophila melanogaster. Mol. Cell. Biol. 29, 6341-6352. doi: 10.1128/MCB.00675-09

Diangelo, J. R., Bland, M. L., Bambina, S., Cherry, S., and Birnbaum, M. J. (2009). The immune response attenuates growth and nutrient storage in Drosophila by reducing insulin signaling. Proc. Natl. Acad. Sci. U.S.A. 106, 20853-20858. doi: 10.1073/pnas.0906749106

Dillin, A., Crawford, D. K., and Kenyon, C. (2002). Timing requirements for insulin/IGF-1 signaling in C. elegans. Science 298, 830-834. doi: $10.1126 /$ science. 1074240

Du, K., Herzig, S., Kulkarni, R. N., and Montminy, M. (2003). TRB3: a tribbles homolog that inhibits Akt/PKB activation by insulin in liver. Science 300, 1574-1577. doi: 10.1126/science.1079817

Dupont, J., and Holzenberger, M. (2003). Biology of insulin-like growth factors in development. Birth Defects Res. C. Embryo Today 69, 257-271. doi: 10.1002/bdrc.10022

Elchebly, M., Payette, P., Michaliszyn, E., Cromlish, W., Collins, S., Loy, A. L., et al. (1999). Increased insulin sensitivity and obesity resistance in mice lacking the protein tyrosine phosphatase-1B gene. Science 283, 1544-1548. doi: $10.1126 /$ science.283.5407.1544

Emerson, K. J., Bradshaw, W. E., and Holzapfel, C. M. (2009). Complications of complexity: integrating environmental, genetic and hormonal control of insect diapause. Trends Genet. 25, 217-225. doi: 10.1016/j.tig.2009. 03.009

Fayard, E., Tintignac, L. A., Baudry, A., and Hemmings, B. A. (2005). Protein kinase B/Akt at a glance.
J. Cell. Sci. 118, 5675-5678. doi: 10.1242 /jcs. 02724

Felix, T. M., Hughes, K. A., Stone, E. A., Drnevich, J. M., and Leips, J. (2012). Age-specific variation in immune response in Drosophila melanogaster has a genetic basis. Genetics 191， 989-1002. doi 10.1534/genetics.112.140640

Fernandez, R., Tabarini, D., Azpiazu, N., Frasch, M., and Schlessinger, J. (1995). The Drosophila insulin receptor homolog: a gene essential for embryonic development encodes two receptor isoforms with different signaling potential. $E M B O$ J. 14, 3373-3384.

Flatt, T., Heyland, A., Rus, F., Porpiglia, E., Sherlock, C., Yamamoto, R. et al. (2008a). Hormonal regulation of the humoral innate immune response in Drosophila melanogaster. J. Exp. Biol. 211, 2712-2724. doi: 10.1242/jeb.014878

Flatt, T., Min, K. J., D'alterio, C., VillaCuesta, E., Cumbers, J., Lehmann, R., et al. (2008b). Drosophila germline modulation of insulin signaling and lifespan. Proc. Natl. Acad. Sci. U.S.A. 105, 6368-6373.

Flatt, T., and Kawecki, T. J. (2007) Juvenile hormone as a regulator of the trade-off between reproduction and life span in Drosophila melanogaster. Evolution 61, 1980-1991. doi: 10.1111/j.15585646.2007.00151.x

Flatt, T., Tu, M. P., and Tatar, M. (2005). Hormonal pleiotropy and the juvenile hormone regulation of Drosophila development and life history. Bioessays 27, 999-1010. doi: 10.1002/bies.20290

Frame, S., Cohen, P., and Biondi, R. M. (2001). A common phosphate binding site explains the unique substrate specificity of GSK3 and its inactivation by phosphorylation. Mol. Cell 7, 1321-1327. doi 10.1016/S1097-2765(01)00253-2

Garsin, D. A., Villanueva, J. M. Begun, J., Kim, D. H., Sifri, C. D., Calderwood, S. B., et al. (2003). Long-lived C. elegans daf- 2 mutants are resistant to bacterial pathogens. Science 300, 1921. doi: 10.1126/science. 1080147

Gershman, B., Puig, O., Hang, L., Peitzsch, R. M., Tatar, M., and Garofalo, R. S. (2007). Highresolution dynamics of the transcriptional response to nutrition in Drosophila: a key role for dFOXO. Physiol. Genomics 29, 24-34. doi: 10.1152/physiolgenomics.00061.2006

Giannakou, M. E., and Partridge, L. (2007). Role of insulin-like signalling in Drosophila lifespan.
Trends Biochem. Sci. 32, 180-188. doi: 10.1016/j.tibs.2007.02.007

Giannakou, M. E., Goss, M., Junger, M. A., Hafen, E., Leevers, S. J., and Partridge, L. (2004). Long-lived Drosophila with overexpressed $\mathrm{dFOXO}$ in adult fat body. Science 305, 361. doi: 10.1126/science. 1098219

Goberdhan, D. C., Paricio, N., Goodman, E. C., Mlodzik, M., and Wilson, C. (1999). Drosophila tumor suppressor PTEN controls cell size and number by antagonizing the Chico/PI3-kinase signaling pathway. Genes Dev. 13, 3244-3258. doi: 10.1101/gad.13.24.3244

Golden, J. W., and Riddle, D. L. (1982). A pheromone influences larval development in the nematode Caenorhabditis elegans. Science 218, 578-580. doi: 10.1126/science.6896933

Golden, J. W., and Riddle, D. L. (1984). The Caenorhabditis elegans dauer larva: developmental effects of pheromone, food, and temperature. Dev. Biol. 102, 368-378. doi: 10.1016/0012-1606(84)90201-X

Goto, S. G. (2013). Roles of circadian clock genes in insect photoperiodism. Entomol. Sci. 16, 1-16. doi: 10.1111/ens. 12000

Goto, S. G., Shiga, S., and Numata, H. (2010). "Photoperiodism in insects: perception of light and the role of clock genes," in Photoperiodism, eds. R J. Nelson, D. L. Denlinger, and D. E. Somers (Oxford: Oxford University Press), 258-286.

Gottlieb, S., and Ruvkun, G. (1994). daf-2, daf-16 and daf-23: genetically interacting genes controlling Dauer formation in Caenorhabditi elegans. Genetics 137, 107-120.

Gracey, A. Y., Fraser, E. J., Li, W., Fang, Y., Taylor, R. R., Rogers, J. et al. (2004). Coping with cold: an integrative, multitissue analysis of the transcriptome of a poikilothermic vertebrate. Proc. Natl. Acad. Sci. U.S.A. 101, 16970-16975. doi: 10.1073/pnas.0403627101

Gronke, S., Clarke, D. F., Broughton, S., Andrews, T. D., and Partridge, L. (2010). Molecular evolution and functional characterization of Drosophila insulin-like peptides. PLoS Genet. 6:e1000857. doi: 10.1371/journal.pgen.1000857

Hahn, D. A., and Denlinger, D. L. (2007). Meeting the energetic demands of insect diapause: nutrient storage and utilization. J. Insect Physiol. 53, 760-773. doi: 10.1016/j.jinsphys.2007.03.018

Hahn, D. A., and Denlinger, D. L. (2011). Energetics of diapause. Annu. Rev. Entomol. 56, 103-121. 
doi: 10.1146/annurev-ento-112408085436

Hamilton, B., Dong, Y., Shindo, M., Liu, W., Odell, I., Ruvkun, G., et al. (2005). A systematic RNAi screen for longevity genes in C. elegans. Genes Dev. 19, 1544-1555. doi: $10.1101 /$ gad.1308205

Hanada, M., Feng, J., and Hemmings, B. A. (2004). Structure, regulation and function of PKB/AKT-a major therapeutic target. Biochim. Biophys. Acta 1697, 3-16. doi: 10.1016/j.bbapap.2003.11.009

Hand, S. C., Menze, M. A., Borcar, A., Patil, Y., Covi, J. A., Reynolds, J. A., et al. (2011). Metabolic restructuring during energy-limited states: insights from Artemia franciscana embryos and other animals. J. Insect Physiol. 57, 584-594. doi: 10.1016/j.jinsphys.2011.02.010

Hardie, J., Baker, F. C., Jamieson, G. C., Lees, A. D., and Schooley, D. A. (1985). The Identification of an aphid juvenile hormone, and its titer in relation to photoperiod. Physiol. Ent. 10, 297-302. doi: 10.1111/j.13653032.1985.tb00050.x

Harrington, L. S., Findlay, G. M., Gray, A., Tolkacheva, T., Wigfield, S., Rebholz, H., et al. (2004). The TSC1-2 tumor suppressor controls insulin-PI3K signaling via regulation of IRS proteins. J. Cell Biol. 166, 213-223. doi: 10.1083/jcb.200403069

Harris, T. E., and Lawrence, J. C. Jr. (2003). TOR signaling. Sci. STKE 2003:re15.

Herman, W. S. (1981). Studies on the adult reproductive diapause of the monarch butterfly, Danaus plexippus. Biol. Bull. 160, 89-106. doi: 10.2307/1540903

Herman, W. S., and Tatar, M. (2001). Juvenile hormone regulation of longevity in the migratory monarch butterfly. Proc. Biol. Sci. 268, 2509-2514. doi: 10.1098/rspb.2001.1765

Honda, Y., and Honda, S. (1999). The daf-2 gene network for longevity regulates oxidative stress resistance and Mn-superoxide dismutase gene expression in Caenorhabditis elegans. FASEB J. 13, 1385-1393.

Hsu, H. J., LaFever, L., and Drummond-Barbosa, D. (2008). Diet controls normal and tumorous germline stem cells via insulindependent and -independent mechanisms in Drosophila. Dev. Biol. 313, 700-712. doi: 10.1016/j.ydbio.2007.11.006

Hwangbo, D. S., Gershman, B., Tu, M. P., Palmer, M., and Tatar, M. (2004). Drosophila dFOXO controls lifespan and regulates insulin signalling in brain and fat body. Nature 429, 562-566. doi: 10.1038/ nature 02549

Ikeno, T., Tanaka, S. I., Numata, H., and Goto, S. G. (2010). Photoperiodic diapause under the control of circadian clock genes in an insect. $B M C$ Biol. 8:116. doi: 10.1186/1741-70078-116

Ikeya, T., Galic, M., Belawat, P., Nairz, K., and Hafen, E. (2002). Nutrientdependent expression of insulin-like peptides from neuroendocrine cells in the CNS contributes to growth regulation in Drosophila. Curr. Biol. 12, 1293-1300. doi: 10.1016/S09609822(02)01043-6

Ito, C., Goto, S. G., Shiga, S., Tomioka, K., and Numata, H. (2008). Peripheral circadian clock for the cuticle deposition rhythm in Drosophila melanogaster. Proc. Natl. Acad. Sci. U.S.A. 105, 8446-8451. doi: 10.1073/pnas.0800145105

Junger, M. A., Rintelen, F., Stocker, H., Wasserman, J. D., Vegh, M., Radimerski, T., et al. (2003). The Drosophila forkhead transcription factor FOXO mediates the reduction in cell number associated with reduced insulin signaling. J. Biol. 2, 20. doi: 10.1186/1475-4924-2-20

Kapahi, P., Zid, B. M., Harper, T., Koslover, D., Sapin, V., and Benzer, S. (2004). Regulation of lifespan in Drosophila by modulation of genes in the TOR signaling pathway. Curr. Biol. 14, 885-890. doi: 10.1016/j.cub. 2004.03.059

Kapan, N., Lushchak, O. V., Luo, J., and Nassel, D. R. (2012). Identified peptidergic neurons in the Drosophila brain regulate insulin-producing cells, stress responses and metabolism by coexpressed short neuropeptide $\mathrm{F}$ and corazonin. Cell $\mathrm{Mol}$ Life Sci. 69, 4051-4066. doi: 10.1007/s00018-012-1097-z

Khani, A., and Moharramipour, S. (2010). Cold hardiness and supercooling capacity in the overwintering larvae of the codling moth, Cydia pomonella. J. Insect Sci. 10, 83. doi: 10.1673/031.010.8301

Kimura, K. D., Tissenbaum, H. A., Liu, Y., and Ruvkun, G. (1997). daf-2, an insulin receptor-like gene that regulates longevity and diapause in Caenorhabditis elegans. Science 277, 942-946. doi: 10.1126/science.277.5328.942

Kitisin, K., Saha, T., Blake, T., Golestaneh, N., Deng, M., Kim, C., et al. (2007). Tgf-Beta signaling in development. Sci. STKE 2007:cm1. doi: $10.1126 /$ stke. $3992007 \mathrm{cml}$
Kops, G. J., Dansen, T. B., Polderman, P. E., Saarloos, I., Wirtz, K. W. Coffer, P. J., et al. (2002a). Forkhead transcription factor FOXO3a protects quiescent cells from oxidative stress. Nature 419, 316-321. doi: 10.1038 /nature01036

Kops, G. J., Medema, R. H., Glassford, J., Essers, M. A., Dijkers, P. F., Coffer, P. J., et al. (2002b). Control of cell cycle exit and entry by protein kinase B-regulated forkhead transcription factors. $\mathrm{Mol}$. Cell. Biol. 22, 2025-2036. doi: 10.1128/MCB.22.7.2025-2036.2002

Kostal, V. (2011). Insect photoperiodic calendar and circadian clock: independence, cooperation, or unity. J. Insect Physiol. 57, 538-556. doi: 10.1016/j.jinsphys. 2010.10.006

Kostal, V., and Denlinger, D. L. (2011). Dormancy and developmental arrest in invertebrates. J. Insect Physiol. 57, 537. doi: 10.1016/j.jinsphys.2011.04.001

Kramer, J. M., Davidge, J. T., Lockyer, J. M., and Staveley, B. E. (2003). Expression of Drosophila FOXO regulates growth and can phenocopy starvation. BMC Dev. Biol. 3:5. doi: 10.1186/1471-213X-3-5

Lee, K. S., Kwon, O. Y., Lee, J. H., Kwon, K., Min, K. J., Jung, S. A., et al. (2008). Drosophila short neuropeptide $\mathrm{F}$ signalling regulates growth by ERK-mediated insulin signalling. Nat. Cell Biol. 10, 468-475. doi: $10.1038 /$ ncb 1710

Leevers, S. J. (2001). Growth control: invertebrate insulin surprises! Curr. Biol. 11, R209-R212. doi: 10.1016/S0960-9822(01)00107-5

LeFever, L., and Drummond-Barbosa, D. (2005). Direct control of germline stem cell division and cyst growth by neural insulin in Drosophila. Science 309, 1071-1073. doi: 10.1126/science. 1111410

Libina, N., Berman, J. R., and Kenyon, C. (2003). Tissue-specific activities of C. elegans DAF-16 in the regulation of lifespan. Cell 115, 489-502. doi: 10.1016/S0092-8674 (03)00889-4

Logan, C. Y., and Nusse, R. (2004). The Wnt signaling pathway in development and disease. Annu. Rev. Cell Dev. Biol. 20, 781-810. doi: 10.1146/annurev.cellbio.20.010403. 113126

Luckhart, S., and Riehle, M. A. (2007). The insulin signaling cascade from nematodes to mammals: insights into innate immunity of Anopheles mosquitoes to malaria parasite infection. Dev. Comp. Immunol. 31, 647-656. doi: 10.1016/j.dci.2006.10.005
Macrae, T. H. (2010). Gene expression, metabolic regulation and stress tolerance during diapause. Cell. Mol. Life Sci. 67, 2405-2424. doi: 10.1007/s00018-010-0311-0

Masaki, S. (1980). Summer diapause. Annu. Rev. Entomol. 25, 1-25. doi: 10.1146/annurev.en.25.010180. 000245

McDonald, M. J., Rosbash, M., and Emery, P. (2001). Wild-type circadian rhythmicity is dependent on closely spaced $\mathrm{E}$ boxes in the Drosophila timeless promoter. Mol. Cell. Biol. 21, 1207-1217. doi: 10.1128/MCB.21.4.1207-1217.2001

McElwee, J. J., Schuster, E., Blanc, E., Thornton, J., and Gems, D. (2006) Diapause-associated metabolic traits reiterated in long-lived daf-2 mutants in the nematode Caenorhabditis elegans. Mech. Ageing Dev. 127, 458-472. doi: 10.1016/j.mad.2006.01.006

Meelkop, E., Temmerman, L., Schoofs, L., and Janssen, T. (2011). Signalling through pigment dispersing hormone-like peptides in invertebrates. Prog. Neurobiol. 93, 125-147. doi: 10.1016/j.pneurobio.2010.10.004

Meuti, M. E., and Denlinger, D. L. (2013). Evolutionary links between circadian clocks and photoperiodic diapause in insects. Integ. Comp. Biol. 53, 131-143. doi: 10.1093/icb/ict023

Michaud, M. R., and Denlinger, D. L. (2006). Oleic acid is elevated in cell membranes during rapid coldhardening and pupal diapause in the flesh fly, Sarcophaga crassipalpis. J. Insect Physiol. 52, 1073-1082. doi: 10.1016/j.jinsphys.2006.07.005

Michaud, M. R., and Denlinger, D. L. (2007). Shifts in the carbohydrate, polyol, and amino acid pools during rapid cold-hardening and diapause-associated cold-hardening in flesh flies (Sarcophaga crassipalpis): a metabolomic comparison. J. Comp. Physiol. B 177, 753-763. doi: 10.1007/s00360-007-0172-5

Miller, B. S., Shankavaram, U. T., Horney, M. J., Gore, A. C., Kurtz, D. T., and Rosenzweig, S. A. (1996). Activation of cJun NH2-terminal kinase/stress-activated protein kinase by insulin. Biochemistry 35 , 8769-8775. doi: 10.1021/bi952651r

Murphy, C. T., Mccarroll, S. A., Bargmann, C. I., Fraser, A., Kamath, R. S., Ahringer, J., et al. (2003). Genes that act downstream of DAF-16 to influence the lifespan of Caenorhabditis elegans. Nature 424, 277-283. doi: 10.1038/nature01789

Murray, P., Hayward, S. A., Govan, G. G., Gracey, A. Y., and Cossins, A. 
R. (2007). An explicit test of the phospholipid saturation hypothesis of acquired cold tolerance in Caenorhabditis elegans. Proc. Natl. Acad. Sci. U.S.A. 104, 5489-5494. doi: 10.1073/pnas.0609590104

Numata, H., and Udaka, H. (2010). "Photoperiodism in Mollusks" in Photoperiodism, eds R. J. Nelson, D. L. Denlinger, and D. E. Somers (Oxford: Oxford University Press), 173-192.

Oh, S. W., Mukhopadhyay, A., Dixit, B. L., Raha, T., Green, M. R., and Tissenbaum, H. A. (2006). Identification of direct DAF-16 targets controlling longevity, metabolism and diapause by chromatin immunoprecipitation. Nat. Genet. 38, 251-257. doi: $10.1038 /$ ng 1723

Partridge, L., Piper, M. D., and Mair, W. (2005). Dietary restriction in Drosophila. Mech. Ageing Dev. 126, 938-950. doi: 10.1016/j.mad.2005.03.023

Poelchau, M. F., Reynolds, J. A., Denlinger, D. L., Elsik, C. G., and Armbruster, P. A. (2011). A de novo transcriptome of the Asian tiger mosquito, Aedes albopictus, to identify candidate transcripts for diapause preparation. BMC Genomics 12:619. doi: 10.1186/1471-2164-12-619

Puig, O., Marr, M. T., Ruhf, M. L., and Tjian, R. (2003). Control of cell number by Drosophila FOXO: downstream and feedback regulation of the insulin receptor pathway. Genes Dev. 17, 2006-2020. doi: 10.1101/gad.1098703

Raff, R. (1996). The Shape of Life: Genes, Development, and the Evolution of Animal Form. Chicago, IL: University Chicago Press.

Ragland, G. J., Denlinger, D. L., and Hahn, D. A. (2010). Mechanisms of suspended animation are revealed by transcript profiling of diapause in the flesh fly. Proc. Natl. Acad. Sci. U.S.A. 107, 14909-14914. doi: 10.1073/pnas.1007075107

Ragland, G. J., Egan, S. P., Feder, J. L., Berlocher, S. H., and Hahn, D. A. (2011). Developmental trajectories of gene expression reveal candidates for diapause termination: a key life-history transition in the apple maggot fly Rhagoletis pomonella. J. Exp. Biol. 214, 3948-3959. doi: 10.1242/jeb.061085

Reynolds, J. A., Poelchau, M. F., Rahman, Z., Armbruster, P. A., and Denlinger, D. L. (2012). Transcript profiling reveals mechanisms for lipid conservation during diapause in the mosquito, Aedes albopictus.
J. Insect Physiol. 58, 966-973. doi: 10.1016/j.jinsphys.2012.04.013

Robich, R. M., and Denlinger, D. L. (2005). Diapause in the mosquito Culex pipiens evokes a metabolic switch from blood feeding to sugar gluttony. Proc. Natl. Acad. Sci. U.S.A. 102, 15912-15917. doi: 10.1073/pnas.0507958102

Rulifson, E. J., Kim, S. K., and Nusse, R. (2002). Ablation of insulinproducing neurons in flies: growth and diabetic phenotypes. Science 296, 1118-1120. doi: $10.1126 /$ science. 1070058

Sano, H., Kane, S., Sano, E., Miinea, C. P., Asara, J. M., Lane, W. S., et al. (2003). Insulin-stimulated phosphorylation of a Rab GTPaseactivating protein regulates GLUT4 translocation. J. Biol. Chem. 278, 14599-14602. doi: 10.1074/jbc.C300063200

Saunders, D. S. (2010) "Photoperiodism in insects: migration and diapause responses" in Photoperiodism, eds R. J. Nelson, D. L. Denlinger and D. E. Somers (Oxford: Oxford University Press), 218-257.

Saunders, D. S. (2012). Insect photoperiodism: seeing the light. Physiol. Entomol. 37, 207-218. doi: 10.1111/j.1365-3032.2012.00837.x

Savory, F. R., Sait, S. M., and Hope, I. A. (2011). DAF-16 and Delta9 desaturase genes promote cold tolerance in long-lived Caenorhabditis elegans age-1 mutants. PLoS ONE 6:e24550. doi: 10.1371/journal.pone.0024550

Schmidt, P. S., Matzkin, L., Ippolito, M., and Eanes, W. F. (2005). Geographic variation in diapause incidence, lifehistory traits, and climatic adaptation in Drosophila melanogaster. Evolution 59, 1721-1732.

Shiga, S., and Numata, H. (2000). The role of neurosecretory neurons in the pars intercerebralis and pars lateralis in reproductive diapause of the blowfly, Protophormia terraenovae. Naturwissenschaften 87, 125-128. doi: 10.1007/s001140050689

Shimokawa, K., Numata, H., and Shiga, S. (2008). Neurons important for the photoperiodic control of diapause in the bean bug, Riptortus pedestris. J. Comp. Physiol. A 194, 751-762. doi: 10.1007/s00359-0080346-y

Shmookler Reis, R. J., Xu, L., Lee, H., Chae, M., Thaden, J. J., Bharill, P. et al. (2011). Modulation of lipid biosynthesis contributes to stress resistance and longevity of C. elegans mutants. Aging (Albany NY) 3 , 125-147.
Sim, C., and Denlinger, D. L. (2008). Insulin signaling and FOXO regulate the overwintering diapause of the mosquito Culex pipiens. Proc. Natl. Acad. Sci. U.S.A. 105, 6777-6781. doi: 10.1073/pnas. 0802067105

Sim, C., and Denlinger, D. L. (2009a). A shut-down in expression of an insulin-like peptide, ILP-1, halts ovarian maturation during the overwintering diapause of the mosquito Culex pipiens. Insect Mol. Biol. 18, 325-332. doi 10.1111/j.1365-2583.2009.00872.x

Sim, C., and Denlinger, D. L. (2009b). Transcription profiling and regulation of fat metabolism genes in diapausing adults of the mosquito Culex pipiens. Physiol. Genomics 39, 202-209. doi: 10.1152/physiolgenomics.00095.2009

Sim, C., and Denlinger, D. L. (2011). Catalase and superoxide dismutase2 enhance survival and protect ovaries during overwintering diapause in the mosquito Culex pipiens. J. Insect Physiol. 57, 628-634. doi: 10.1016/j.jinsphys. 2011.01.012

Sim, C., and Denlinger, D. L. (2013). Juvenile hormone III suppresses forkhead of transcription factor in the fat body and reduces fat accumulation in the diapausing mosquito, Culex pipiens. Insect Mol. Biol. 22, 1-11. doi: 10.1111/j.13652583.2012.01166 $\mathrm{x}$

Soderberg, J. A., Carlsson, M. A., and Nassel, D. R. (2012). Insulin-producing cells in the Drosophila brain also express satiety-inducing cholecystokininlike peptide, drosulfakinin. Front. Endocrinol. (Lausanne) 3:109. doi 10.3389/fendo.2012.00109

Sousa-Nunes, R., Yee, L. L., and Gould, A. P. (2011). Fat cells reactivate quiescent neuroblasts via TOR and glial insulin relays in Drosophila. Nature 471, 508-512. doi: 10.1038/nature09867

Sun, J., Folk, D., Bradley, T. J., and Tower, J. (2002). Induced overexpression of mitochondrial Mn-superoxide dismutase extends the life span of adult Drosophila melanogaster. Genetics 161, 661-672.

Tammariello, S. P., and Denlinger D. L. (1998). $\mathrm{G}_{0} / \mathrm{G}_{1}$ cell cycle arrest in the brain of Sarcophaga crassipalpis during pupal diapause and the expression pattern of the cell cycle regulator, Proliferating Cell Nuclear Antigen. Insect Biochem. Mol. Biol. 28, 83-89. doi: 10.1016/S0965-1748(97)00082-9
Taniguchi, C. M., Emanuelli, B., and Kahn, C. R. (2006). Critical nodes in signalling pathways: insights into insulin action. Nat Rev. Mol. Cell Biol. 7, 85-96. doi: 10.1038/nrm1837

Tatar, M., Kopelman, A., Epstein, D., Tu, M. P., Yin, C. M., and Garofalo, R. S. (2001). A mutant Drosophila insulin receptor homolog that extends life-span and impairs neuroendocrine function. Science 292, 107-110. doi: 10.1126/science. 1057987

Tatar, M., and Yin, C. (2001). Slow aging during insect reproductive diapause: why butterflies, grasshoppers and flies are like worms. Exp. Gerontol. 36, 723-738. doi: 10.1016/S0531-5565(00)00238-2

Tauber, M. J., Tauber, C. A., and Masaki, S. (1986). Seasonal Adaptations of Insects. New York, NY: Oxford University Press.

Tu, M. P., Yin, C. M., and Tatar, M. (2005). Mutations in insulin signaling pathway alter juvenile hormone synthesis in Drosophila melanogaster. Gen. Comp. Endocrinol. 142, 347-356. doi: 10.1016/j.ygcen.2005.02.009

Ueki, K., Kondo, T., and Kahn, C. R. (2004). Suppressor of cytokine signaling 1 (SOCS-1) and SOCS-3 cause insulin resistance through inhibition of tyrosine phosphorylation of insulin receptor substrate proteins by discrete mechanisms. Mol. Cell. Biol. 24, 5434-5446. doi: $\quad$ 10.1128/MCB.24.12.54345446.2004

Vafopoulou, X., Cardinal-Aucoin, M., and Steel, C. G. (2012). Rhythmic release of prothoracicotropic hormone from the brain of an adult insect during egg development. Comp. Biochem. Physiol. A Mol. Integr. Physiol. 161, 193-200. doi: 10.1016/j.cbpa.2011.10.026

Vafopoulou, X., Steel, C. G., and Terry, K. L. (2007). Neuroanatomical relations of prothoracicotropic hormone neurons with the circadian timekeeping system in the brain of larval and adult Rhodnius prolixus (Hemiptera). J. Comp. Neurol. 503, 511-524. doi: 10.1002/cne.21393

Vanfleteren, J. R., and De Vreese, A. (1995). The gerontogenes age-1 and daf- 2 determine metabolic rate potential in aging Caenorhabditis elegans. FASEB J. 9, 1355-1361.

Vereshchagina, N., Ramel, M. C., Bitoun, E., and Wilson, C. (2008). The protein phosphatase PP2A-B' subunit Widerborst is a negative regulator of cytoplasmic activated Akt and lipid metabolism 
in Drosophila. J. Cell. Sci. 121, 3383-3392. doi: 10.1242/jcs. 035220

Vesala, L., and Hoikkala, A. (2011). Effects of photoperiodically induced reproductive diapause and cold hardening on the cold tolerance of Drosophila montana. J. Insect Physiol. 57, 46-51. doi: 10.1016/j.jinsphys.2010.09.007

Walker, G. A., and Lithgow, G. J. (2003). Lifespan extension in C. elegans by a molecular chaperone dependent upon insulin-like signals. Aging Cell 2, 131-139. doi: 10.1046/j.14749728.2003.00045.x

Wang, J., and Kim, S. K. (2003). Global analysis of dauer gene expression in Caenorhabditis elegans. Development 130, 1621-1634. doi: 10.1242/dev.00363

Wang, M. C., Bohmann, D., and Jasper, H. (2005). JNK extends life span and limits growth by antagonizing cellular and organism-wide responses to insulin signaling. Cell 121, 115-125. doi: 10.1016/j.cell.2005.02.030
Watanabe, H., Pan, Z. Q., SchreiberAgus, N., Depinho, R. A., Hurwitz, J., and Xiong, Y. (1998). Suppression of cell transformation by the cyclin-dependent kinase inhibitor p57KIP2 requires binding to proliferating cell nuclear antigen. Proc. Natl. Acad. Sci. U.S.A. 95, 1392-1397. doi: 10.1073/pnas.95.4.1392

Williams, K. D., Busto, M., Suster, M. L., So, A. K., Ben-Shahar, Y., Leevers, S. J., et al. (2006). Natural variation in Drosophila melanogaster diapause due to the insulin-regulated PI3-kinase. Proc. Natl. Acad. Sci. U.S.A. 103, 15911-15915. doi: 10.1073/pnas.0604592103

Williams, K. D., Schmidt, P. S., and Sokolowski, M. B. (2010). "Photoperiodism in insects: molecular basis and consequences of diapause" in Photoperiodism, eds R. J. Nelson, D. L. Denlinger and D. E. Somers (Oxford: Oxford University Press), 287-317.
Wittwer, F., Jaquenoud, M., Brogiolo, W., Zarske, M., Wustemann, P., Fernandez, R., et al. (2005). Susi, a negative regulator of Drosophila PI3-kinase. Dev. Cell 8, 817-827. doi: 10.1016/j.devcel. 2005.04.002

Xu, W. H., Lu, Y. X., and Denlinger, D. L. (2012). Cross-talk between the fat body and brain regulates insect developmental arrest. Proc. Natl. Acad. Sci. U.S.A. 109, 14687-14692. doi: 10.1073/pnas. 1212879109

Zhang, H., Liu, J., Li, C. R., Momen, B., Kohanski, R. A., and Pick, L. (2009). Deletion of Drosophila insulin-like peptides causes growth defects and metabolic abnormalities. Proc. Natl. Acad. Sci. U.S.A. 106, 19617-19622. doi: 10.1073/pnas. 0905083106

Zheng, X., and Sehgal, A. (2010). AKT and TOR signaling set the pace of the circadian pacemaker. Curr. Biol. 20, 1203-1208. doi: 10.1016/j.cub.2010.05.027
Conflict of Interest Statement: The authors declare that the research was conducted in the absence of any commercial or financial relationships that could be construed as a potential conflict of interest.

Received: 26 April 2013; paper pending published: 26 May 2013; accepted: 30 June 2013; published online: 22 July 2013.

Citation: Sim $C$ and Denlinger DL (2013) Insulin signaling and the regulation of insect diapause. Front. Physiol. 4:189. doi: 10.3389/fphys.2013.00189 This article was submitted to Frontiers in Invertebrate Physiology, a specialty of Frontiers in Physiology.

Copyright (c) 2013 Sim and Denlinger. This is an open-access article distributed under the terms of the Creative Commons Attribution License, which permits use, distribution and reproduction in other forums, provided the original authors and source are credited and subject to any copyright notices concerning any third-party graphics etc. 